\title{
Indoor and Outdoor Concentrations of Particulate Matter and Gaseous Pollutants on Different Floors of a University Building: A Case Study
}

\author{
Robert Cichowicz ${ }^{1 *}$, Maciej Dobrzański ${ }^{1}$ \\ 1 Faculty of Architecture, Civil and Environmental Engineering, Lodz University of Technology, Al. Politechniki 6, \\ 90-924 Lodz, Poland \\ * Corresponding author's e-mail: robert.cichowicz@p.lodz.pl
}

\begin{abstract}
In this study, we investigate the changes in the concentrations of suspended particulate matter $\left(\mathrm{PM}_{10}\right.$ and $\left.\mathrm{PM}_{25}\right)$ and selected gaseous pollutants (VOCs, $\mathrm{H}_{2} \mathrm{~S}$ ) in the atmospheric air inside and outside a 9-story building, which is intended primarily for the teaching activities. The purpose was to determine whether the air quality inside the building is directly dependent on the outside air quality. The analysis also included the influence of the height of the building, its location and environment, as well as meteorological conditions. No clear correlation was found between the measured parameters inside and outside the building. The height above ground (the floor on which the measurements were made) was found to have a significant influence on the concentration of each pollutant. Wind direction was also found to have a very important impact on the air quality inside the building. A strong relationship was observed on the leeward side between the concentration of impurities on the inside and outside of the building.
\end{abstract}

Keywords: Air quality monitoring, $\mathrm{VOCs}, \mathrm{H}_{2} \mathrm{~S}, \mathrm{PM}_{10}, \mathrm{PM}_{2.5}$, indoor and outdoor air quality

\section{INTRODUCTION}

The concentration of suspended particulate matter is one of the basic parameters used to assess the air quality. Directive 2008/50/EC categorizes particulate matter into small $\left(\mathrm{PM}_{10}\right)$ and very small $\left(\mathrm{PM}_{2.5}\right)$ particles. According to the World Health Organization, PM is one of the most harmful air pollutants [World Health Organization 2013]. They are generated mainly by anthropogenic factors and are particularly pervasive in large human clusters, such as urban agglomerations and highly industrialized regions [Frankowski, 2020; Cichowicz et al., 2020]. Suspended particulate matter may contain harmful heavy metals, for example as a result of burning fossil fuels during the heating season or by industry [Lewandowska et al., 2018; Widziewicz et al., 2018], as well as microorganisms such as bacteria or molds [Frąk et al., 2014]. Pollutants of this size may enter not only the human lungs, causing allergies and respiratory disorders [Hamra et al., 2014; Pira \& Piolatto, 2013; Qiu et al., 2014], but also the bloodstream, having detrimental effects [Fuks et al., 2011; Nawrot et al., 2011]. Other hazardous substances that may occur in the air are gaseous pollutants such as hydrogen sulfide, sulfur and nitrogen oxides, carbon monoxide, and volatile organic compounds (VOC) [Su et al., 2013].

Volatile organic compounds (VOCs) are a diverse group of organic chemicals that are ubiquitous in most urban environments. For example, benzene is a group 1 carcinogen, according to the classification of the International Agency Research on Cancer [IARC, 2016]. Due to the ease with which gaseous pollutants can enter into buildings, and living organisms via the lungs, they pose a significant health risk [Wu et al., 2017]. For this reason, as part of control and prevention, the concentrations of these pollutants should be monitored constantly 
in order to assess the state of air quality [Zeger et al., 2008; Fang et al., 2020]. In the event of hazardous air conditions, it is recommended to stay indoors, at homes, schools, or offices, and to avoid excessive contact with the outside air. However, the question arises whether houses, workplaces, and schools are in fact safe from external pollution, and if there may be a direct relationship between the air quality inside and outside buildings [Su et al., 2013].

A large proportion of the city population in Central and Eastern Europe (42.3\%) lives in multi-story buildings located on housing estates. These are dominated by two types of buildings: tenement houses and blocks with 4-5 stories and skyscrapers between 8 and 11 stories high. Urban buildings of different heights cause the formation of air corridors and swirls, as well as under- and overpressure zones, depending on the direction and speed of the wind [Hong et al., 2017; Cichowicz \& Wielgosiński, 2015b]. When assessing the impact of external conditions on the indoor air quality, the surroundings of the building, including its distance from green areas, other buildings, and transport routes, should also be considered [Tong et al., 2016; Cichowicz \& Wielgosiński, 2015b]. Relative altitude may therefore also have an effect on the concentration of the indoor air pollutants.

In this study, we investigated the effects of altitude above the ground level on the concentrations of dust and gas pollutants outside and inside a building. We also analyzed the influence of the local surroundings, wind direction, and windspeed on the concentration of pollutants in the air.

\section{MATERIALS AND METHODS}

\section{Measuring apparatus and sampling location}

The analysis of the air quality inside and outside the building was performed using specialized equipment for measuring $\mathrm{PM}_{10}, \mathrm{PM}_{2.5}, \mathrm{H}_{2} \mathrm{~S}$ and VOCs. The eight-sensor measuring and sampling module for the measurement of dust and gaseous pollutants in atmospheric air is equipped with the following sensors: $\mathrm{PM}_{10}, \mathrm{PM}_{2.5}$, and $\mathrm{PM}_{1.0}(10,000$ Particles/Sec, sensor type: Laser Scattered), $\mathrm{H}_{2} \mathrm{~S}$ (3ppb-1ppm, sensor type: EC), organic solvents (Ethanol, Iso-Butane, $\mathrm{H}_{2}, 0-500 \mathrm{ppm}$, sensor type: $\mathrm{MOS}), \mathrm{O}_{2}(0.2-100 \%$, sensor type: $\mathrm{EC}$ - Electrochemical), $\mathrm{SO}_{2}$ (0.5-2000 ppm, sensor type: EC) and odors (0.5-1000 ppm isobutanol, sensor type: MOS). The sensors are connected to the system for filling the laboratory bag with air and the ground station.

Air quality analysis was carried out in a building belonging to the Faculty of Civil Engineering, Architecture and Environmental Engineering at Lodz University of Technology, located in the city of Lodz in Poland, in Central-Eastern Europe. The city of Lodz is the third largest city in Poland in terms of population, with 67,9491 inhabitants, an area of $293.25 \mathrm{~km}^{2}$, and a population density of $2,318.6$ people $/ \mathrm{km}^{2}$. The city is dominated by 4-5-story buildings, with some taller ones. Building "B6" is located on the " $\mathrm{B}$ " campus of Lodz University of Technology. It is a 9-story building, used mainly for the teaching activities. The top floor is intended for the technical purposes. Story 0 (ground floor) and each story $(1-8)$ is about $3.5 \mathrm{~m}$ high. The building is surrounded to the north and east by a wooded park, up to the height of $14 \mathrm{~m}$. At a distance of about $15 \mathrm{~m}$ from the west, there is a 4-story faculty building, "B7", and at a distance of $30 \mathrm{~m}$ from the south the analyzed building (B6) adjoins the 4-story "B9" faculty building (Fig. 1). Within a radius of $300 \mathrm{~m}$, there are skyscrapers of similar height to the object of analysis.

Measurements were made inside and outside building B6, on stories $0,2,4,6$, and 8 on the north and south sides (Fig. 2). These points were selected to observe the possible impact of the surroundings and the altitude on the concentrations of selected pollutants. In order to eliminate the influence of direct human factors on the concentration level, measurements were taken on the dates when few students and employees were present in the building, and their impact was therefore negligible.

\section{METEOROLOGICAL DATA OF MEASUREMENTS}

Meteorological conditions are an important consideration for an air quality analysis. Using the available resources, the wind speed and direction, precipitation, temperature, and atmospheric pressure were recorded. Table 1 presents the selected representative measurement series/days, illustrating the typical meteorological conditions over the analyzed period. The article presents three series of measurements: A, B and C. Series 


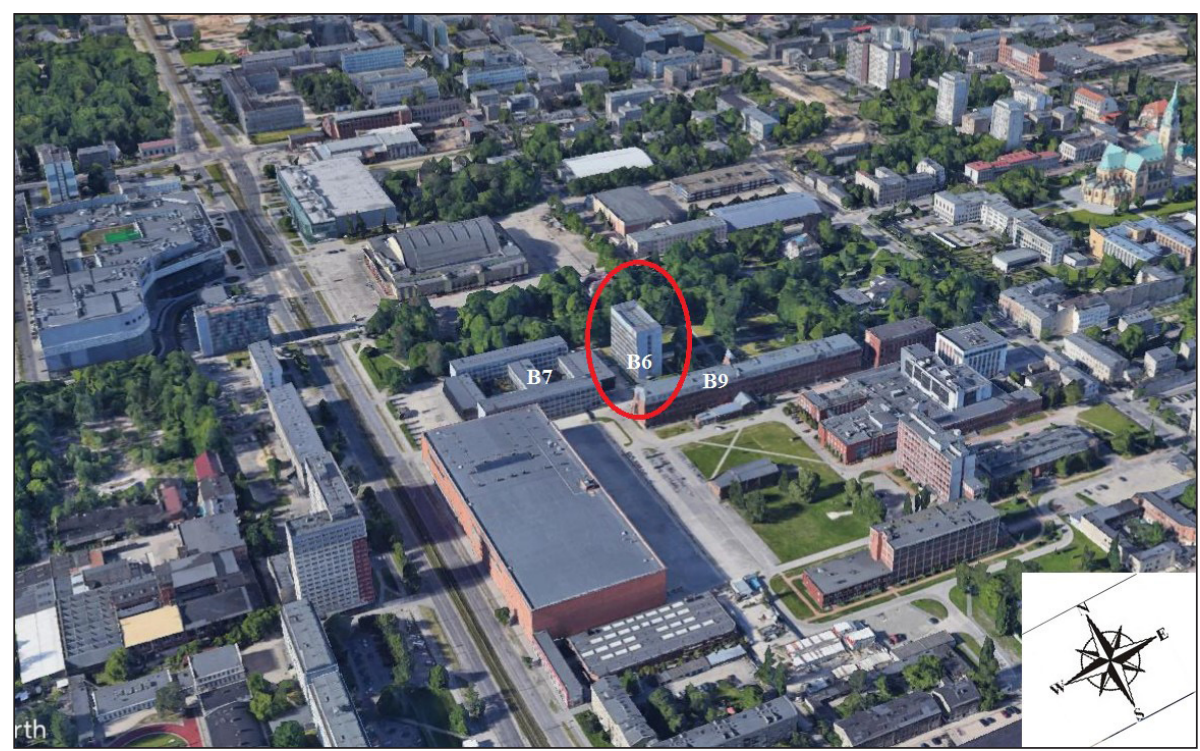

Fig. 1. Location and surroundings of building "B6" on campus "B" of Lodz University of Technology (photo source: www.google.com/maps)

A, B and C were conducted consecutively. Series $\mathrm{C}$ differs from the $\mathrm{A}$ and $\mathrm{B}$ series not only in terms of the meteorological conditions, but also due to the renovations that were taking place inside the building.

\section{RESULTS AND DISCUSSIONS}

The first of the three series of measurements, Series A, was performed on the north side of the building adjacent to the park. This series of measurements, which was carried out on $01 / 24 / 2020$ from 8:00 a.m. to 4:00 p.m., represents typical meteorological and weather conditions for this period and location. The conditions, with a dominant south-westerly wind with a moderate speed of $7 \mathrm{~m} / \mathrm{s}$, little cloud cover (23.6\%), and no precipitation, were conducive to the displacement of particulate matter pollutants. Figure 3A shows the changes in the $\mathrm{PM}_{10}$ and $\mathrm{PM}_{2.5}$ parameters in relation to the height of the measurement points inside and outside the building from the park side (north side). The changes are clearly more intense outside the building than inside. Up to a height of about $16 \mathrm{~m}$ above the ground level inside the facility, the parameter values do not change significantly. The concentration of pollutants decreases
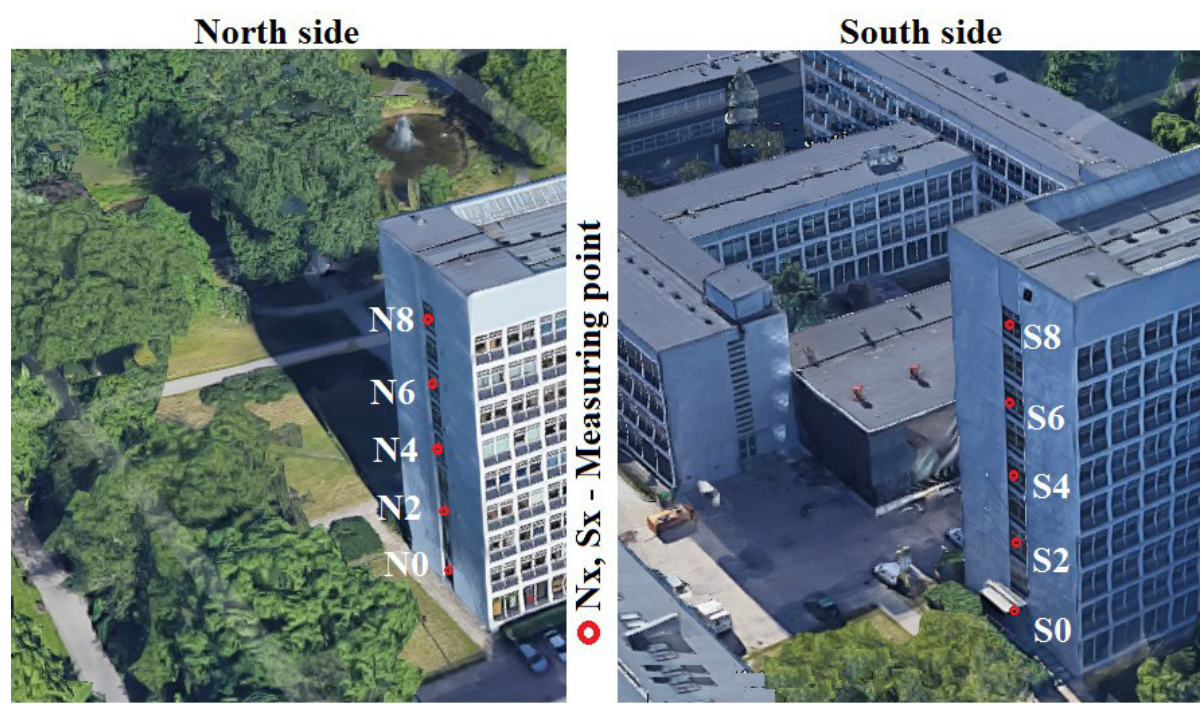

Fig. 2. Location of measurement points on the elevation view south and north (photo source: www.google.com/maps) 
Table 1. Meteorological data for measurement series

\begin{tabular}{|c|c|c|c|c|c|c|c|c|c|c|}
\hline \multicolumn{2}{|l|}{ Series } & \multicolumn{3}{|c|}{ A } & \multicolumn{3}{|c|}{ B } & \multicolumn{3}{|c|}{ C } \\
\hline \multicolumn{2}{|l|}{ Date } & \multicolumn{3}{|c|}{24.01 .2020} & \multicolumn{3}{|c|}{31.01 .2020} & \multicolumn{3}{|c|}{07.02 .2020} \\
\hline Parameters & Unit & Min & Max & Average & Min & Max & Average & Min & Max & Average \\
\hline $\begin{array}{l}\text { Temperature } \\
{[2 \mathrm{~m} \text { above gnd] }}\end{array}$ & ${ }^{\circ} \mathrm{C}$ & -1.08 & 2.81 & 1.8 & 6.38 & 8.19 & 7.6 & 0.07 & 1.46 & 0.95 \\
\hline $\begin{array}{l}\text { Relative Humidity } \\
\text { [2 m above gnd] }\end{array}$ & $\%$ & 61 & 89 & 69.0 & 79 & 94 & 86.1 & 35 & 66 & 44 \\
\hline $\begin{array}{l}\text { Mean Sea Level } \\
\text { Pressure [MSL] }\end{array}$ & $\mathrm{hPa}$ & 1021.7 & 1026.2 & 1023.9 & 996.5 & 1002.9 & 999.1 & 1029.3 & 1030.9 & 1030.0 \\
\hline $\begin{array}{l}\text { Total Precipitation } \\
\text { (high resolution) [sfc] }\end{array}$ & $\mathrm{mm}$ & 0 & 0 & 0.0 & 0 & 0.2 & 0.0 & 0 & 0 & 0 \\
\hline Total Cloud Cover & $\%$ & 0 & 56 & 23.6 & 100 & 100 & 100 & 0 & 0 & 0 \\
\hline $\begin{array}{l}\text { Wind Speed } \\
{[10 \mathrm{~m} \text { above gnd] }}\end{array}$ & $\mathrm{km} / \mathrm{h}$ & 18.46 & 31.75 & 25.13 & 32.43 & 37.02 & 35.26 & 10.18 & 18.09 & 14.19 \\
\hline $\begin{array}{l}\text { Wind Direction } \\
\text { [10 m above gnd] }\end{array}$ & $\circ$ & - & - & 240 & - & - & 281 & - & - & 43 \\
\hline $\begin{array}{l}\text { Wind Direction } \\
\text { [10 } \mathrm{m} \text { above gnd] }\end{array}$ & - & - & - & WSW & - & - & WNW & - & - & NE \\
\hline
\end{tabular}

only on story 6 , by about $13 \%$ compared to the other measurement points. This can be explained by the air turbulence outside the building, which was caused by the surrounding buildings with heights of 4 to 8 stories. The fall in the concentration of pollutants is most marked in the external measurement data. Above $15 \mathrm{~m}$ (4 stories), the outdoor particulate matter concentration increases by an average of $18 \%$, then decreases by as much as $35 \%$. It finally increases by $20 \%$ at a height of $30 \mathrm{~m}$. The highest concentrations of $\mathrm{PM}_{10}$ and $\mathrm{PM}_{2.5}$ were recorded on floor 0 . Overall, the concentration of particulate matter pollution fell along with the altitude outside the building.

It should be emphasized (Fig. 3A) that, as in other studies [Lim et al., 2011; Romagnoli et al., 2016], the concentration of pollutants inside the building was lower than the concentration outside, by an average of $36 \%$ for $\mathrm{PM}_{10}$ and by $42 \%$ for $\mathrm{PM}_{2.5}$. The most important purpose of this study was to analyze the correlation between the concentration of pollutants inside and outside the building. The values for the adjustment coefficient $\mathrm{R}^{2}$ presented in Table 2 at levels from 0.55 to 0.69 do not enable a direct correlation to be drawn between the concentrations of dust inside and outside the building in relation to the height. Other researchers have arrived at similar conclusions [Meier et al., 2015]. However, a strong correlation can be inferred between the data, with the Pearson's ' $r$ ' values above 0.50 .

Th second series of data, series $\mathrm{B}$, consists of measurements taken during cloudy weather with more than $10 \mathrm{~km} / \mathrm{h}$ stronger windspeed (compared to series A) These factors translated into much lower concentrations of the analyzed pollutants than in the previous series, with an almost eightfold decrease (Fig. 3B). The curves for the changes in the values of $\mathrm{PM}_{10}$ and $\mathrm{PM}_{2.5}$ inside and outside the building in relation to the height were similar. However, the concentrations inside the building were lower than those outside, which is in line with the results of other studies [Romagnoli et al., 2016]. For $\mathrm{PM}_{2.5}$, the highest value was $20 \%$ greater, and the lowest value for $\mathrm{PM}_{10}$ was lower by $17 \%$ in relation to the external concentration. A similar dependence was recorded in the previous measurement series, but the differences were larger. Taking into account the influence of altitude, to a height of $16 \mathrm{~m}$ the concentrations of the measure pollutants outside the building decreased by up to $50 \%\left(\mathrm{PM}_{2.5}\right.$ in relation to the concentration at a height of $2 \mathrm{~m}$ ) and then increased from the height of $30 \mathrm{~m}$. Interestingly, the concentration of pollutants inside the building decreased from 2 to 16 meters, by about $60 \%\left(\mathrm{PM}_{2.5}\right)$. A further change in height did not significantly change the concentration. This can be explained by the meteorological conditions-strong winds and high humidity. During the period in which the measurements were taken, the particulate matter pollution occurred mainly at lower altitudes, which translated into higher concentrations of particulate matter inside the building relative to the external conditions. This phenomenon has also been reported by [Monlar et al., 2007]. Our results show a high coefficient of determination of $0.90-0.93$ and a strong correlation from 0.949 to 0.964 between the concentrations of $\mathrm{PM}_{2.5}$ and $\mathrm{PM}_{10}$, respectively, measured outside 

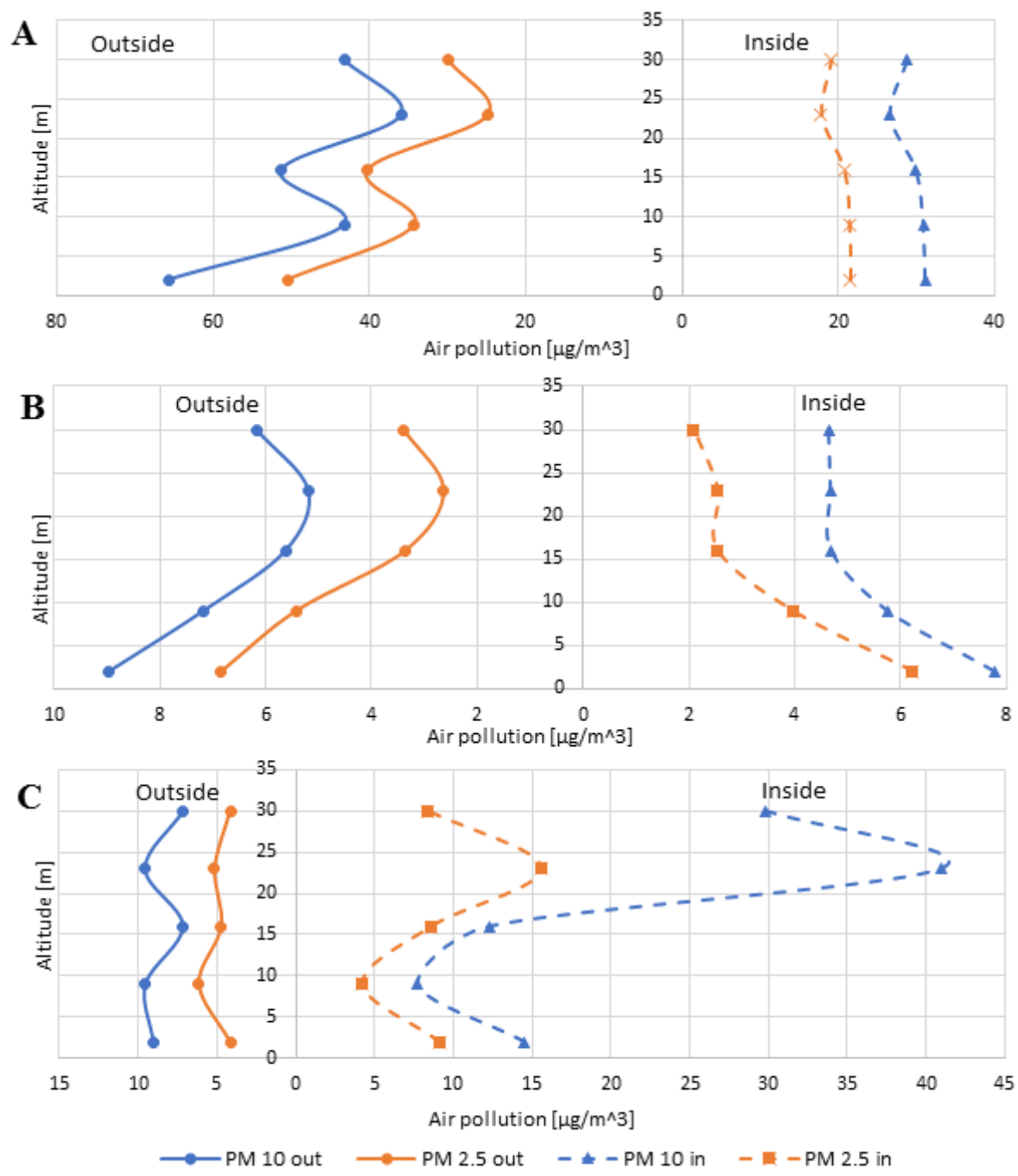

Fig. 3. Comparison of the $\mathrm{PM}_{10}$ and $\mathrm{PM}_{2.5}$ parameters outside and inside the building on the north side, depending on the height of the measurement point in three measurement series

and inside the building from the north (Table 2). In this case, the north was the windward side.

Figure $3 \mathrm{C}$ presents the results of measurement series $\mathrm{C}$, during which renovation work constituted a large emitter of pollutants in the building. On the sixth floor, the auditorium rooms were being renovated, generating significant amounts of particulate matter. This translated into a $40 \%$ increase in the concentration of pollutants compared to the typical concentration at the height of $23 \mathrm{~m}$ inside the building, to over $40 \mu \mathrm{g} / \mathrm{m}^{3}$ for $\mathrm{PM}_{10}$. This confirms the significant influence of internal pollution sources on the concentration of PM, as has also been observed by Zhu et al. [2005]. The ongoing renovation work also contributed to high concentrations of dust on the fourth and eighth floors of the building. Given the low correlation coefficients, of -0.285 and 0.049 for $\mathrm{PM}_{2.5}$ and $\mathrm{PM}_{10}$, respectively, no regularity can be found between the measured data inside and outside the building (Table 2). Only the high concentration of dust pollutants at a height of $23 \mathrm{~m}$ corresponds to the higher concentration measured outside the building. This can be explained by particulate matter escaping to the outside through the window joinery in the direction of the wind.

The next group of analyzed parameters were gaseous air pollutants, including volatile organic compounds (VOCs) and hydrogen sulfide $\left(\mathrm{H}_{2} \mathrm{~S}\right)$.

Figure $4 \mathrm{~A}$ shows that outside the building on the north side, the concentration of $\mathrm{H}_{2} \mathrm{~S}$ decreased with respect to height, whereas the concentration of VOCs increased. The explanation may be that the density of $\mathrm{H}_{2} \mathrm{~S}$ is higher than that of air, whereas the density of VOCs is lower, so the highest concentration for $\mathrm{H}_{2} \mathrm{~S}$ was recorded at the lowest altitude and the highest concentration of VOCs was recorded at an altitude of $30 \mathrm{~m}$. In 
Table 2. Coefficient of correlation and matching between the values outside and inside the building on the north side for the $\mathrm{PM}_{10}, \mathrm{PM}_{2.5}, \mathrm{H}_{2} \mathrm{~S}$, and VOCs parameters for three measurement series

\begin{tabular}{|c|c|c|c|c|c|c|}
\hline Series & \multicolumn{2}{|c|}{$\mathrm{A}$} & \multicolumn{2}{c|}{$\mathrm{B}$} & \multicolumn{2}{c|}{$\mathrm{C}$} \\
\hline Parameters & $\mathrm{r}$ & $\mathrm{R}^{2}$ & $\mathrm{r}$ & $\mathrm{R}^{2}$ & $\mathrm{r}$ & $\mathrm{R}^{2}$ \\
\hline $\mathrm{PM} \mathrm{10}$ & 0.741 & 0.550 & 0.964 & 0.930 & 0.049 & 0.002 \\
\hline $\mathrm{PM} 2.5$ & 0.829 & 0.688 & 0.949 & 0.901 & -0.285 & 0.082 \\
\hline $\mathrm{H}_{2} \mathrm{~S}$ & $0.588^{*}$ & $0.617^{*}$ & 0.853 & 0.728 & 0.289 & 0.0836 \\
\hline VOC & $0.996^{*}$ & $0.992^{*}$ & 0.592 & 0.772 & 0.920 & 0.847 \\
\hline *without 0 floor - gastronomic point
\end{tabular}

the data collected inside the building, no similar relationships were found. The highest concentrations of VOCs were recorded on the ground floor, which may be related to the operation during this period of a catering point in the north-western part of the building. It may also have been due to the greatest number of people being on the ground floor [Fromme et al. 2008]. On the next stories, the concentration of VOCs decreased in relation to the ground floor level by about $50 \%$ and remained similar to a height of $23 \mathrm{~m}$. Only on the last stories did the level increase again, by about $45 \%$. This may have been due to the VOCs floating upstream. It should be emphasized that the VOCs concentration inside the building was on average $42 \%$ higher than that outside, excluding the measurements on the top floor. Researchers in Spain similarly observed a higher concentration
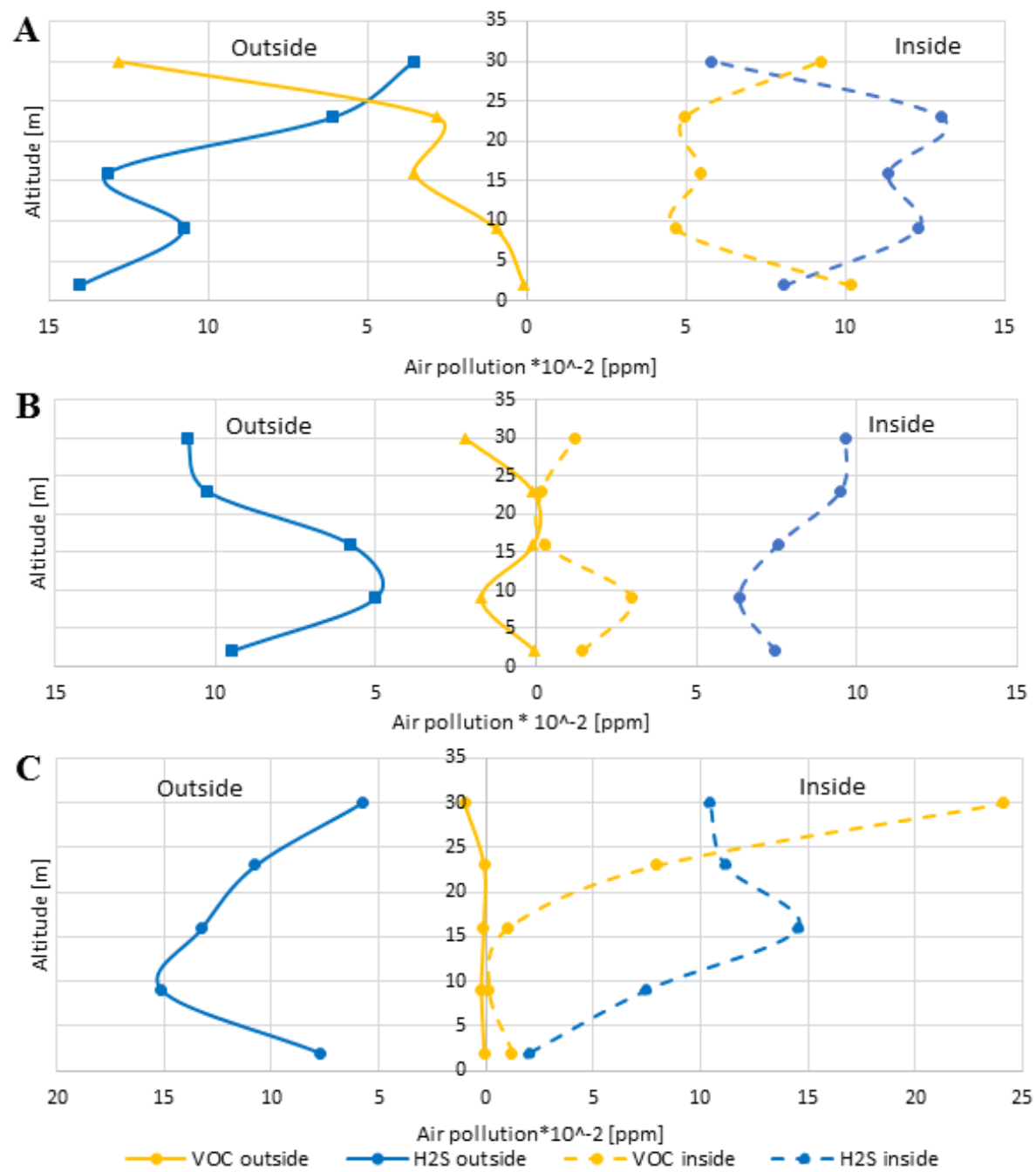

Fig. 4. Comparison of the parameters $\mathrm{H}_{2} \mathrm{~S}$ and VOCs outside and inside the building on the north side depending on the height of the measurement point in the three measurement series, A, B and C 
of chemical compounds inside school rooms [Pallares et al., 2019]. This may be due to the internal pollution sources [Zwoździak et al., 2013]. A very close order of magnitude of the inside to outside concentrations was measured for $\mathrm{H}_{2} \mathrm{~S}$. A significant exception was on the ground floor, where the lowest concentration of $\mathrm{H}_{2} \mathrm{~S}$ was measured inside the building and the highest outside.

A very strong correlation of more than 0.5 was noted between the concentration of gaseous pollutants outside and inside the building (Table 2). In series B, high VOCs concentrations were measured at a height of $9 \mathrm{~m}$ both outside the building and inside, which may have been due to the wind direction. Similarly to the measurements in series A, on the upper stories, up to 20-fold increase in the VOCs concentration was observed at the height of $30 \mathrm{~m}$. The change in the $\mathrm{H}_{2} \mathrm{~S}$ concentration in relation to the height was similar to that in series A. Starting from the initial height of $2 \mathrm{~m}$, the concentration of $\mathrm{H}_{2} \mathrm{~S}$ decreased to the height of $9 \mathrm{~m}$, and then increased to the last floor. Inside the building, the change in the $\mathrm{H}_{2} \mathrm{~S}$ concentration was smaller than that outside. In series $\mathrm{B}$, as in series A, a strong correlation was noted between the values for gaseous pollutants inside and outside the building (Table 2). The ongoing renovation during the measurement series $\mathrm{C}$ also influenced the concentration of $\mathrm{H}_{2} \mathrm{~S}$ and volatile organic compounds inside the facility (Fig. 4C). The VOCs concentration at a height of $30 \mathrm{~m}$ inside the object was 24 times higher than that measured outside. Outside the building, the VOCs concentration was at a low and almost constant level. Only on the top floor, there was a 9-fold increase in the VOCs concentration. Due to the fact that the windspeed did not exceed $5 \mathrm{~m} / \mathrm{s}$ during the measurement period, the concentration of $\mathrm{H}_{2} \mathrm{~S}$ outside the facility from the park side reached the highest value at a height of about $9 \mathrm{~m}$. Above $9 \mathrm{~m}$, a decrease in the concentration of $\mathrm{H}_{2} \mathrm{~S}$ was observed. As in measurement series A and B, series $\mathrm{C}$ also showed a higher concentration of VOCs inside the object than outside, and the correlation coefficient was close to 1 (Table 2). These results are consistent with the those reported by Raysoni et al. [2017], who suggested that the sources of higher VOCs concentrations inside buildings might include the use of cleaning agents, furniture polishes, and materials used in arts and crafts.

On the southern side of the building, there are numerous academic buildings. In series A, the maximum concentration of particulate matter pollutants outside and inside was found at a height of $2 \mathrm{~m}$. Inside the building, on the upper floors, the concentrations of $\mathrm{PM}_{10}$ and $\mathrm{PM}_{2.5}$ did not change and were lower than those on the ground floor by approximately $27 \%$. As on the north side, the indoor concentration was lower, by an average of $39 \%$ and $44 \%$ for $\mathrm{PM}_{10}$ and $\mathrm{PM}_{2.5}$, respectively, compared to the conditions outdoors. In series A, the southern side of the building was the windward side. This could have been a cause of the higher correlations between the PM concentrations measured inside and outside the building (Table 3). The average determination coefficient was 0.98 , and the correlation coefficient was close to 1 . In addition, the particulate matter concentration was about $20 \%$ lower inside the building on the south side than on the north side, depending on the height, and there was also a lower concentration of particulate matter outside.

The changes in the concentrations of particulate matter pollutants outside the building recorded in series B are similar to those recorded in measurement series $\mathrm{A}$. The highest concentration was measured at a height of $2 \mathrm{~m}$ (Fig. 5B). The particulate matter concentrations outside the building tended to decrease with increasing altitude. However, there are two points, at the heights of $16 \mathrm{~m}$ (fourth floor) and $30 \mathrm{~m}$ (eighth floor), where the concentration suddenly increases. Inside the building, there were no significant changes in the concentrations of $\mathrm{PM}_{2.5}$ and $\mathrm{PM}_{10}$ at these heights. This can be explained by the ventilation zones, which are related to the heights of the surrounding buildings. On the leeward side (the southern side in series B), the difference between the concentrations of pollutants indoors and outdoors was only around $8 \%$. Inside the building, the concentration of $\mathrm{PM}_{25}$ and $\mathrm{PM}_{10}$ varied within a very narrow range, similarly to the measurements in series A. In the case of $\mathrm{PM}_{10}$, the concentration for stories two and four increased by about $6 \%$ compared to the ground floor, followed by a decrease of $9 \%$ on the eighth story. Slight changes in the concentrations of particulate matter pollutants inside the building relative to the significant changes occurring outside led to a lack of correlation between the data. This is evidenced by correlation coefficients of close to zero, at 0.226 and -0.015 for $\mathrm{PM}_{10}$ and $\mathrm{PM}_{2.5}$, respectively (Table 3).

In series $\mathrm{C}$, outside the building (southern side) a slight decrease of about $13 \%$ in the concentration of $\mathrm{PM}_{10}$ was observed as the height increased from $2 \mathrm{~m}$ to $23 \mathrm{~m}$ and a significant 

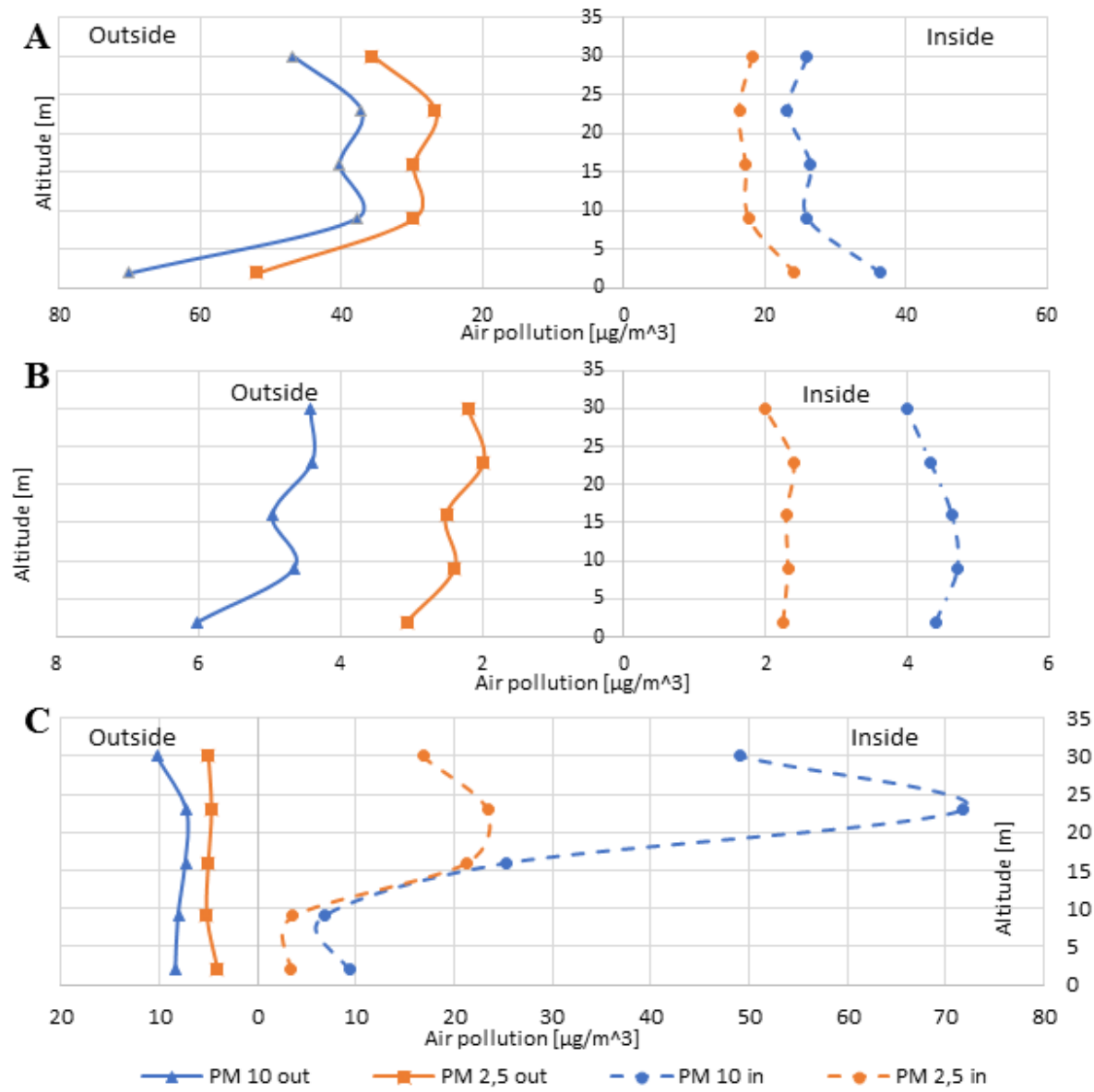

- PM 2,5 out

$--\mathrm{PM} 10$ in $\quad-\rightarrow$ PM 2,5 in

Fig. 5. Comparison of the $\mathrm{PM}_{10}$ and $\mathrm{PM}_{2.5}$ parameters outside and inside the building on the southern side relative to the height of the measurement points in three measurement series, A, B and C

increase of about $40 \%$ was found between the heights of $23 \mathrm{~m}$ and $30 \mathrm{~m}$ (Fig. 5C). This can be explained by the direction of the wind, which was blocked by a 4 -story building and by $6-8$-story buildings further away. These buildings presented a barrier to the movement of dust in the light wind (average wind speed about $5 \mathrm{~m} / \mathrm{s}$ ). The concentration of $\mathrm{PM}_{10}$ pollution increased only above the height of the buildings (over $23 \mathrm{~m}$ ). In the case of the lighter $\mathrm{PM}_{2.5}$ fraction, the changes outside the building were not significant. The changes in the particulate matter concentration in relation to the height inside the building on the south side were very similar to those recorded on the north side. The highest concentrations of $\mathrm{PM}_{10}$, over $70 \mu \mathrm{g} / \mathrm{m}^{3}$, were measured on the floor where renovations were taking place (height $23 \mathrm{~m}$ ). This also caused a high concentration of PM at altitudes of $16 \mathrm{~m}$ and $30 \mathrm{~m}$. Inside the building on the southern side, more than $40 \%$ higher particulate matter concentration was found compared to the north side. The reason was the location of the auditoriums under renovation, which are closer to the south. From the southern side of the building, no particulate matter pollution was blown outside, as it was on the northern side. This can probably be explained by the direction of the wind, as the southern side was leeward. Again, due to

Table 3. Coefficient of correlation and matching between values for the $\mathrm{PM}_{10}, \mathrm{PM}_{2.5}, \mathrm{H}_{2} \mathrm{~S}$, and VOCs parameters outside and inside the building on the southern side over three measurement series

\begin{tabular}{|c|c|c|c|c|c|c|}
\hline Series & \multicolumn{2}{|c|}{$\mathrm{A}$} & \multicolumn{2}{c|}{$\mathrm{B}$} & \multicolumn{2}{c|}{$\mathrm{C}$} \\
\hline Parameters & $\mathrm{r}$ & $\mathrm{R}^{2}$ & $\mathrm{r}$ & $\mathrm{R}^{2}$ & $\mathrm{r}$ & $\mathrm{R}^{2}$ \\
\hline $\mathrm{PM} \mathrm{10}$ & 0.990 & 0.981 & 0.226 & 0.051 & 0.009 & 0.00008 \\
\hline PM 2.5 & 0.989 & 0.977 & -0.015 & 0.0002 & 0.311 & 0.0964 \\
\hline $\mathrm{H}_{2} \mathrm{~S}$ & -0.614 & 0.377 & 0.792 & 0.628 & 0.153 & 0.0235 \\
\hline VOC & 0.938 & 0.879 & 0.638 & 0.991 & 0.335 & 0.1121 \\
\hline
\end{tabular}


the internal emitter of pollutants, there is no direct correlation between the indoor and outdoor data. The highest values for the linear determination coefficient, at only 0.0964 , and for the correlation coefficient, at 0.311 , were obtained for $\mathrm{PM}_{2.5}$, indicating no relationship between the analyzed data (Table 3). Other researchers have made similar observations [Mohammadyan et al., 2017; Romagnoli et al., 2016].

Similar changes were observed in the concentrations of gaseous pollutants outside the building on the southern side (Fig. 6A) to those on the opposite side (Fig. 4A). However, the situation inside the building was strikingly different. In series A, the concentration of VOCs decreased about 6-fold from the height of $0 \mathrm{~m}$ to $16 \mathrm{~m}$, and then increased 35-fold, reaching the highest value on the top floor. In the case of $\mathrm{H}_{2} \mathrm{~S}$, the concentration inside increased with height, contrary to the changes in the concentration outside. This translates into a high correlation coefficients for VOCs and $\mathrm{H}_{2} \mathrm{~S}$ measurements outside and inside, amounting to 0.938 for VOCs, and -0.614 for $\mathrm{H}_{2} \mathrm{~S}$ (Table 3). In series A, the concentration of VOCs was higher inside the building than outside.

The change in the concentration of gaseous air pollutants in series B was different from that recorded in series A (Fig.6). The maximum VOCs concentration inside and outside the building was measured at a height of $16 \mathrm{~m}$, not on the top floor as it was in series A. However, it should be emphasized that changes in the $\mathrm{H}_{2} \mathrm{~S}$ and VOCs concentrations with relative to the height on the south side were consistent with the observations on the north side of the building. The only difference was that the highest VOCs concentrations on the south side were on the fourth floor, as opposed to on the second floor on the north side. Dense cloud cover, 4-story buildings in the vicinity, and the fact it was the heating period, may have caused the high VOCs concentrations at the height of $16 \mathrm{~m}$. Again, strong correlations were found between the inside and outside concentrations of both $\mathrm{H}_{2} \mathrm{~S}$ and VOCs, at 0.792 and 0.638 ,
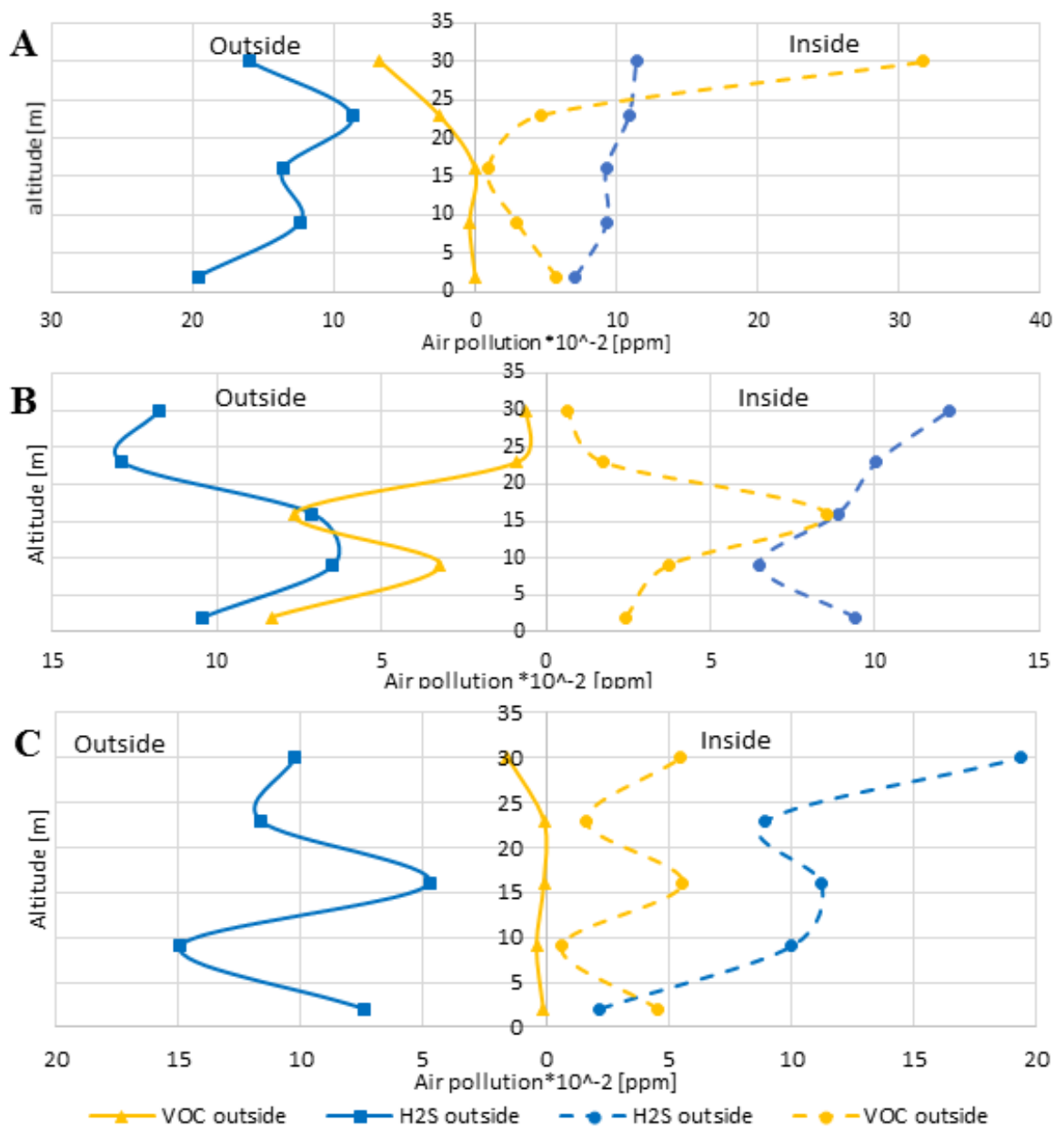

Fig. 6. Comparison of the parameters $\mathrm{H}_{2} \mathrm{~S}$ and VOCs outside and inside the building on the south side relative to the height of the measurement points in series A, B and C 
respectively (Table 3). In a previous study, Raysoni et al. [2017] also noted a strong correlation between the concentrations of VOCs outside and inside a building, at $0.63<\mathrm{r}<1.00$.

The third measurement series (Fig. 6C) on the southern side shows similar results outside the building to those recorded in series A (Fig. 6A). The VOCs concentration was relatively constant up to a height of $23 \mathrm{~m}$. A significant increase (more than 23-fold) in the concentration of VOCs occurred at the height of $30 \mathrm{~m}$. In contrast, the concentration of $\mathrm{H}_{2} \mathrm{~S}$ varied widely from about $5^{*} 10^{-2} \mathrm{ppm}$ to $15^{*} 10^{-2} \mathrm{ppm}$. The changes in the concentrations of VOCs and $\mathrm{H}_{2} \mathrm{~S}$ inside the building relative to height recorded in series $\mathrm{C}$ were different from those recorded in the other series, due to the ongoing renovation work. However, the VOCs concentration was again higher inside the building than on the outside, and the concentration of $\mathrm{H}_{2} \mathrm{~S}$ tended to increase with height. Due to the clear differences between the data, unlike the other series, a weak correlation was found in series $\mathrm{C}$ between the concentrations of gaseous pollutants and VOCs measured outside and inside the building.

\section{CONCLUSION}

In this study, we investigated the changes in the concentrations of suspended particulate matter $\left(\mathrm{PM}_{10}\right.$ and $\left.\mathrm{PM}_{2.5}\right)$ and selected gaseous pollutants (VOCs, $\mathrm{H}_{2} \mathrm{~S}$ ) in the atmospheric air inside and outside a 9-story building on a university campus. Significantly smaller fluctuations in the $\mathrm{PM}_{10}$ and $\mathrm{PM}_{25}$ concentrations in relation to the height were noted inside the building than outside. This was due to the separation of the stories (despite the existence of a staircases). The only exception was when there were considerable pollutants inside the building, in this case due to renovations which released large amounts of particulate matter into the air. Then, through passageways and leaks, the particulate matter spread to other floors. The concentration of gaseous air pollutants inside the building increased with the altitude. There were deviations from this dependence, resulting from the influence of external conditions. For example, due to a heavy cloud cover during the heating season, high VOCs concentrations were measured in series B on floor 2 on the north side and on floor 4 on the south side. This was related to the heights of the surrounding buildings. The buildings located within a radius of $150 \mathrm{~m}$ from the analyzed structure are 4-5 stories (14-17 m high). The buildings mostly use gravity ventilation, which causes gaseous pollutants to escape from the rooms at the height of the roof.

No direct correlation was found on either side of the building between the concentrations of particulate matter pollutants in the air outside and inside. The sides of the building should be considered individually, in relation to the wind direction and the topography. There was a stronger correlation on the windward side than on the leeward side. It can be generally concluded that the higher the average concentrations of particulate matter pollutants outside the building, the higher the concentrations inside. However, on typical measurement days, the air quality inside the building was better in terms of the particulate matter pollution than the air quality outside the building. The concentration of $\mathrm{PM}_{10}$ and $\mathrm{PM}_{2.5}$ outdoors measured in series A exceeded the permissible level of $50 \mu \mathrm{g} / \mathrm{m}^{3}$ for $\mathrm{PM}_{10}$ and $25 \mu \mathrm{g} / \mathrm{m}^{3}$ for $\mathrm{PM}_{2.5}$ by up to double, on both sides of the building. In the remaining series (B and C), the values were within the acceptable limits. The particulate matter concentration inside did not exceed the permissible Threshold Limit Value (TLV) of $10 \mathrm{mg} / \mathrm{m}^{3}$. This confirms the assumption that building partitions and window frames constituted a barrier reducing the amount of particulate matter pollution entering the building interior. An exception to this was when renovation work constituted an internal pollutant emitter.

The conclusions regarding gaseous pollutants are different. The data show a strong correlation between the concentrations of $\mathrm{H}_{2} \mathrm{~S}$ and VOCs outside and inside the building. Building partitions did not constitute an effective barrier to these pollutants. Moreover, inside the building, the VOCs concentration was up to 24-fold higher than it was outside. Unfortunately, there are no standards in Poland regarding the permissible levels of VOCs in the air. In the case of outside $\mathrm{H}_{2} \mathrm{~S}$, the permissible level of $0.02 \mathrm{mg} / \mathrm{m}^{3}$ was exceeded up to $15-$ fold in all measurement series. However, inside the building, due to the higher permissible concentration of $\mathrm{H}_{2} \mathrm{~S}\left(\mathrm{TLV} 7 \mathrm{mg} / \mathrm{m}^{3}\right)$, the limit was not exceeded.

The elements of the surroundings were not found to have any direct influence on the concentration of air pollutants inside the building. The heights of the surrounding buildings and trees were of greater importance. The data show clear 
changes in the concentrations of particulate matter and gaseous pollutants at the heights of the fourth and eighth stories. This corresponds to the average height of the buildings adjacent to the analyzed object.

\section{Acknowledgement}

This study was conducted as part of the research project entitled "Spatial analysis of air pollution changes in the Lodz agglomeration (in Polish: Analiza przestrzenna zmian stanu zanieczyszczenia powietrza w aglomeracji łódzkiej)", which was co-financed by approx. $80 \%$ by the Provincial Fund for Environmental Protection and Water Management in Lodz (in Polish: Wojewódzki Fundusz Ochrony Środowiska i Gospodarki Wodnej w Łodzi).

\section{REFERENCES}

1. Cichowicz R., Wielgosiński G. 2015a. Effect of meteorological conditions and building location on $\mathrm{CO} 2$ concentration in the university campus. ECOL CHEM ENG S. 22(4):513-525. DOI: 10.1515/ eces-2015-0030.

2. Cichowicz R., Wielgosiński G. 2015b. Effect of urban traffic on the immission of carbon dioxide in the university campus. ECOL CHEM ENG S. 22(2): 189-200. DOI: 10.1515/eces-2015-0010.

3. Cichowicz R., Wielgosiński G., Fetter W. 2020. Effect of wind speed on the level of particulate matter PM10 concentration in atmospheric air during winter season in vicinity of large combustion plant. Journal of Atmospheric Chemistry https://doi. org/10.1007/s10874-020-09401-w.

4. Directive 2008/50/EC of the European Parliament and of the Council of 21 May 2008 On Ambient Air Quality and Cleaner Air for Europe (OJ L 152, 11.6.2008).

5. Fang J., Tang X., Xie R., Han F. 2020. The effect of manufacturing agglomerations on smog pollution. Structural Change and Economic Dynamics Vol. 54, Pages 92-101 https://doi.org/10.1016/j. strueco.2020.04.003.

6. Frankowski J. 2020. Attention: smog alert! Citizen engagement for clean air and its consequences for fuel poverty in Poland. Energy and Buildings. Vol. 207, 109525. https://doi.org/10.1016/j. enbuild.2019.109525.

7. Frąk, M., Majewski, G. \& Zawistowska, K. 2014. Analysis of the quantity of microorganisms adsorbed on particulate matter PM10. Scientific Review Engineering and Environmental Sciences, 23
(2), 140-149.

8. Fromme H, Diemer J, Dietrich S, Cyrys J, Heinrich J, Lang W, et al. 2008. Chemical and morphological properties of particulate matter (PM10, PM2.5) in school classrooms and outdoor air. Atmos Environ 42, 6597e605. https://doi.org/10.1515/ sjph-2017-0031.

9. Fuks, K., Moebus, S., Hertel, S., Viehmann, A., Nonnemacher, M., Dragano, N., \& Heinz Nixdorf Recall Study Investigative Group. 2011. Long-Term Urban Particulate Air Pollution, Traffic Noise, and Arterial Blood Pressure. Environmental Health Perspectives, 119(12), 1706-1711. https://doi. org/10.1289/ehp.1103564.

10. Hamra, G. B., Guha, N., Cohen, A., Laden, F., Raaschou-Nielsen, O., Samet, J. M., \& Loomis, D. 2014. Outdoor Particulate Matter Exposure and Lung Cancer: A Systematic Review and Meta-Analysis. Environmental Health Perspectives, 122(9), 906-911. https://doi.org/10.1289/ehp.1408092.

11. Hong, B., Lin, B., \& Qin, H. 2017. Numerical investigation on the coupled effects of building-tree arrangements on fine particulate matter (PM2.5) dispersion in housing blocks. Sustainable Cities and Society, 34, 358-370. https://doi.org/10.1016/J. SCS.2017.07.005.

12. IARC, 2016. IARC (International Agency for Research on Cancer) Monographs on the Evaluation of Carcinogenic Risks to Human. http://monographs. iarc.fr/ENG/Classification/latest_classif.php. (Accessed 10.08.2020).

13. Lewandowska A.U., Bełdowska M., Witkowska A., Falkowska L., Wiśniewska K. 2018. Mercury bonds with carbon (OC and EC) in small aerosols (PM1) in the urbanized coastal zone of the Gulf of Gdansk (southern Baltic). Ecotoxicology and Environmental Safety. Vol. 157, Pages 350-357. https:// doi.org/10.1016/j.ecoenv.2018.03.097.

14. Lim J.-M., Jeong J.-H., Lee J.-H., Moon J.-H., Chung Y.-S., Kim K.-H. 2011. The analysis of PM2.5 and associated elements and their indoor/outdoor pollution status in an urban area. Indoor Air, 21(2), 145-155. https://doi.org/10.1111/j.1600-0668.2010.00691.x.

15. Meier R., Eeftens M., Phuleria H. C., Ineichen A., Corradi E., Davey M., \& Künzli N. 2015. Differences in indoor versus outdoor concentrations of ultrafine particles, PM2.5, PM absorbance and $\mathrm{NO} 2$ in Swiss homes. Journal of Exposure Science and Environmental Epidemiology, 25(5), 499-505. https://doi.org/10.1038/jes.2015.3.

16. Mohammadyan M., Ghoochani M., Kloog I., Abdul-Wahab S. A., Yetilmezsoy K., Heibati B., Godri Pollitt K. J. 2017. Assessment of indoor and outdoor particulate air pollution at an urban background site in Iran. Environmental Monitoring and Assessment, 189(5), 235. https://doi.org/10.1007/ 
s10661-017-5951-1.

17. Molnar P., Bellander T., Sallsten G., Boman J., 2007. Indoor and outdoor concentrations of PM2.5 trace elements at preschools and schools in Stockholm, Sweden. J. Environ. Monit. 9, 348-357. https://doi. org/10.1039/B616858B.

18. Nawrot, T. S., Perez, L., Kunzli, N., Munters, E., \& Nemery, B. 2011. Public health importance of triggers of myocardial infarction: a comparative risk assessment. The Lancet, 377(9767), 732-740. https://doi.org/10.1016/S0140-6736(10)62296-9.

19. Pallares S., Gomez E., MartínezA., Jordan M., 2019. The relationship between indoor and outdoor levels of PM10 and its chemical composition at schools in a coastal region in Spain. Heliyon 5, e02270, https:// doi.org/10.1016/j.heliyon.2019.e02270.

20. Pira, E., \& Piolatto, P. G. 2013. Outdoor air pollution and lung cancer: what now? Epidemiology, Biostatistics and Public Health, 10(4), https://doi. org/10.2427/9444.

21. Qiu, H., Tian, L. W., Pun, V. C., Ho, K., Wong, T. W., \& Yu, I. T. S. 2014. Coarse particulate matter associated with increased risk of emergency hospital admissions for pneumonia in Hong Kong. Thorax, 69(11), 1027-1033. https://doi.org/10.1136/ thoraxjnl-2014-205429.

22. Raysoni A. U., Stock T. H., Sarnat J. A., Chavez M. C., Sarnat S. E., Montoya T., Holguin F., Li W-W. 2017. Evaluation of VOC concentrations in indoor and outdoor microenvironments at near-road schools. Environmental Pollution 231, 681-693. http://dx.doi.org/10.1016/j.envpol.2017.08.065.

23. Romagnoli P., Balducci C., Perilli M., Vichi F., Imperiali A., Cecinato A. 2016. Indoor air quality at life and work environments in Rome, Italy. Environmental Science and Pollution Research, 23(4), 35033516. https://doi.org/10.1007/s11356-015-5558-4.

24. Su F-Ch., Mukherjee B., Batterman S. 2013. Determinants of personal, indoor and outdoor VOC concentrations: An analysis of the RIOPA data. Environmental Research, 126, 192-203. http://dx.doi. org/10.1016/j.envres.2013.08.005.

25. Tong, Z., Chen, Y., Malkawi, A., Liu, Z., \& Freeman,
R. B. 2016. Energy saving potential of natural ventilation in China: The impact of ambient air pollution. Applied Energy, 179, 660-668. https://doi. org/10.1016/J.APENERGY.2016.07.019.

26. Widziewicz K., Rogula-Kozłowska W., Loska K., Kociszewska K., Majewski G. 2018. Health Risk Impacts of Exposure to Airborne Metals and Benzo(a)Pyrene during Episodes of High PM10 Concentrations in Poland. Biomedical and Environmental Sciences, 31(1), 23-36. https://doi. org/10.3967/bes2018.003.

27. World Health Organization 2013. Review of evidence on health aspects of air pollution -REVIHAAP Project Retrieved from. World Health Organization 309. http://www.euro.who.int/en/ health-topics/environment-and-health/air-quality/ publications/2013/review-of-evidence-on-healthaspects-of-air-pollution-revihaap-project-finaltechnical-report.

28. Wu M. X., Basu R., Malig B., Broadwin R., Ebisu K., Gold B. E., Qi L., Derby C., Green S. R., 2017. Association between gaseous air pollutants and inflammatory, hemostatic and lipid markers in a cohort of midlife women, Environment International, Vol. 107, Pages 131-139, ISSN 0160-4120, https:// doi.org/10.1016/j.envint.2017.07.004.

29. Zeger, S. L., Dominici, F., McDermott, A., \& Samet, J. M. (2008). Mortality in the Medicare Population and Chronic Exposure to Fine Particulate Air Pollution in Urban Centers (2000-2005). Environmental Health Perspectives, 116(12), 1614-1619. https:// doi.org/10.1289/ehp.11449.

30. Zhu Y., Hinds W.C., Krudysz M., Kuhn T., Froines J., Sioutas C., 2005. Penetration of freeway ultrafine particles into indoor environments. Aerosol Sci. 36, 303-322. https://doi.org/10.1016/j. jaerosci.2004.09.007.

31. Zwoździak A., Sówka I., Krupińska B., Zwoździak B., Nych A. 2013. Infiltration or indoor sources as determinants of the elemental composition of particulate matter inside a school in Wroclaw, Poland? Building and Environment 66, 173-180. http:// dx.doi.org/10.1016/j.buildenv.2013.04.023. 